\title{
أثر الاستحسان في المقاصد الخاصة
}

\author{
محمد أغوس جوهري
}

متلحص

إن الأدلة التي تستنبط بها الأحكام الثرعية لأفعال المكلفين نوعان: نوع اتفق العلماء على أنه مصدر من مصادر التشريع الإسلاي، ونوع اختلف العلماء في اعتباره مصدرا تشريعيا.

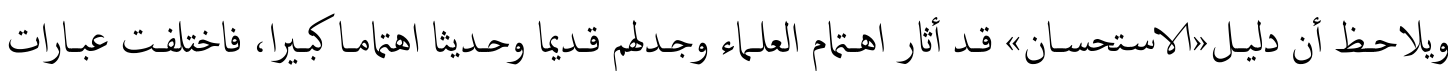

الأصوليين في تحديد مفهومه فنها ما يؤدي إلى معنى مقبول إجاعا، ومنها ما يؤدي إلى معنى مردود إجاعا، ومنه ما هو موضع نظر واجتهاد.

وقال النحراوي:اإن الاستحسان بالرغخ من قدم وجود هذا المصطلح وهو ما يزيد عن ألف سـنة من بدء ظهوره

إلى عصرنا هذا، لم يحظ بتعريف مسـتقر ثابت. وربما هـذا إن دل على شيء فإنما يـل على أن الاستحسـان مبدأ يكتنفه الغموض، أو مصطلح يجتاج إلى دراسة لمعرفة حقيقته، أو أنه متشعب الأركان، ومتعدد النواحي والمناحي ينعـذر حصره في

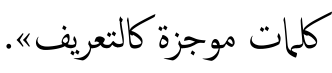
وبالرجوع إلى كتب الأحناف نجد كثيرا ما جرت كلمة الاستحسان على ألسنته بكلمة القياس. فأحيانا يطلق القياس ويراد منه النص الثرعي العام، ومن أمثلته ما جاء عن الإمام أبي حنيفة رضي الله تعالى عنه في رجم الزاني المحصن:»إنا أثتبنا الرجم بالاستحسان على خلاف القياس"، فإن المراد بالقياس هنا النص الثريعي العام. وهو

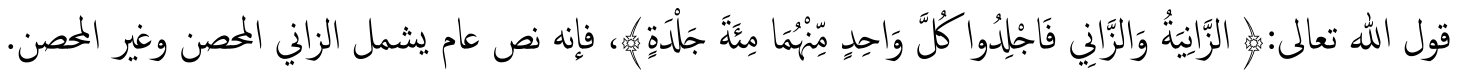
ومن فتناواه التي استخدم فيهاكلمة الاستحسان ـ فتواه فيمن قضى بجلده لثبوت الزنا عليه فلم يكمل عليه الحـد، أو أكمل فشهد شاهدان بإحصانه فإن القياس أن يربج؛ لأنه محصن لكن الإمام أبا حنيفة يقول في ذلك: "والقياس أن يربح ولكنـا نستحسن فيدرأ عنه حد الرجم وما بقي عليه من الحد لأني أكره أن أرجمه وقد أقتت عليه حد الضرب فيكون قد أقيم عليه حدان في زنا واحد فهذا قيح لا يستقيم في الاستحسان". 
وتارة أخرى يطلق القياس ويراد منه القاعدة الثرعية المقررة عند الفقهاء، أو عند بعضهم، ومن أمثلته ما جاء كذلك عن الإمام أبي حنيفة رضي الله عنه فيمن أكل، أو شرب ناسيا»لولا الرواية لقلت بالقياس"، فإن المراد من القياس هنـا أيضـا القاعدة المقررة في الصوم وغيره، ولكن روي عن النبي صلى الله عليه وسلم ما يدل على عدم بطلان الصوم بالأكل، أو الثرب نسيانا، وعمل به أبو حنيفة وترك تطبيق القاعدة العامة على هذه المسألة.

قد عرفنا تعريف المقاصد الخاصة، ولعلماء الشريعة والأصوليين كنابات في هذا المجال، نجد منهم على سبيل المثال كما ذكر جال الدين عطية في كتابه 》نحو تفعيل مقاصد الشريعة《: 1ـ الحكيم التزمذي كتابات عن الصلاة ومقاصدها، والحج وأسراره. 2ـ العز بن عبد السلام بيان أن المقصود من العبادات كلها إجلال الإله وتعظمه ومهابته والتوكل عليه والتفويض إليه. 3ـ ابن عاشور، وقد تحدث في كنابه مقاصد الشريعة الإسلامية، بيان مقاصد أحكام العائلة، ومقاصد التصرفات المالية، ومقاصد المعاملات المنعقدة على عمل الأبدان، ومقاصد أحكام التبرعات، ومقاصد أحكام القضاء والشهادة، ومقاصد العقوبات، وغيرها.

ونعلم أن للمقاصد وسائل، حيث جعل الفقهاء أحكام الوسائل كأحكام المقاصد كما نص على ذلك عدد كير من الفقهاء منهم: العز بن عبد السلام في قوله: ״وللوسائل أحكام المقاصد《. وقبل الثروع في بيان وسائل المقاصد، يستحسن تعريف الوسائل وهي: الأمور التي تسبق المقاصد وتوصل إليها، أو هي الطرق المفضية إليها بحسب وضع الشرع واجتهاد العقل، وذلك على نحو: اشتراط الطهارة وسيلة لصحة الصلاة، وتعظيم الخالق وعبادته، وسيلة لمقصد تمكين الأخلاق في النفس الإنسانية، ومنع البيع في الجمعة وسيلة لمقصد حرمة الصلاة وحضورها... وبأن النية المقرونة بالقول، أو الفعل المنعلق بالحج وسيلة لانعقاد الحج. وتشمل الوسائل الثرعية: التكليف، الأسباب، الثروط، الموانع، الرخص، والذرائع المختلفة، وصيغ العقود والمعاملات،والأسهاء، والألفاظ الدالة على معانيها ومسمياتها،وغير ذلك.

فالوسائل إذن هي كل ما أوصل إلى المقاصد، وهي مرتبطة بها من حيث الحصول وعدمه، وحكمها هو حكم ما أفضت إليه من منع، أو إيجاب أو تحريم، أو تحليل وكما يجب النظر في المقاصد واللنفات إلها، يجب كذلك النظر في طرائقها التي تفضى إليها. ويسقط اعتبار الوسائل ومراعاتها عند سقوط المقاصد وزوالها. 
حظي مبحث وسائل المقاصد بنفس الأهمية التي حظي بها مبحث المقاصد ذانه، وذلك لتوفق تلك المقاصد على

$$
\text { وسائلها الموضوعة لها، وجودا وعدما. }
$$

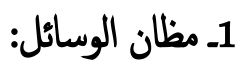

$$
\text { يظن وجود مادة الوسائل ومحتواها في المباحث الآتية: }
$$

1ـ المقاصد: مبحث المقاصد ـ كما هو معلوم ـ هو المبحث الذي تتصل به مباشرة وبداهة مسألة الوسائل، إذ أن المقصد ووسيلته يتلازمان ويتزابطان من حيث الوجود والعدم...1هوارد الأحكام على قسمين: مقاصد وهي متضمنة للمصاح والمفاسد في أنفسها، ووسائل وهي الطرق المفضية إليهاء.

2ـ الأحكام: الأحكام الشرعية وضعت لمقاصدها وأغراضها، فهي طرق ووسائل لتحقيق تلك المقاصد... فالسبب والشرط والمانغ مثلا، لم توضع لذاتها ولم تكن مقصودة في نسها، وإنما وضعت لتحصيل غيرها وتحتيق ما تفضي إليه من مصالح ومناف، ومثال ذلك: اشتراط النية وسيلة لصحة الوضوء والغسل، ورؤية الهلال وسيلة لثبوت الثهر ووجوب الصوم... ومثاله أيضا: موانغ الأحكام على نحو: الإغاء، والجنون والإكراه، والحيض، والنفاس والمرض... فإن تلك الموانع عدها الشع وسائل شرعية معتبرة نبطت بها مقاصدها المتثنلة في دفح المشقة والحرج، وتحتيق التيسير والتخفيف عن المكلفين. 3ـ الذرائع فتحا وسدا: تعد الذرائع فتها وسدا وسائل للمقاصد، إذ ينظر إلى الذريعة وإلى وجوب سدها، أو فتحها بحسب ما ستؤول إليه، أو بحسب الأثر المترتب عليها. 4ـ الحيل والاستحسان وغيرها مما يتعين وسيلة لمقصده بحسب الوعتبار الشرعي وعدمه.

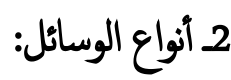

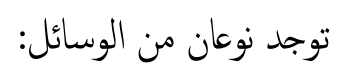

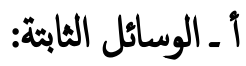

وهي الوسائل التي حددها الشارع طرقا مضبوطة إلى مقاصدها التي لا تتحقق إلا بها، بحيث لو انخرمت الوسائل، أو تغيرت، لانخرمت معها المقاصد واختلت وتغيرت، وهذا النوع من الوسائل موجود بكثرة في خطاب الشارع وتعالمه، وهو يشمل جملة الأحكام الوضعية، وكيفيات وتفاصيل العبادات، وأصول الفضائل والمعاملات، وقواعد ومسائل الاعتقاد، وغير ذلك من الأمور التي جعلها الشارع وسائل لتحصيل مقاصدها. 
ومن أمثلة هذا النوع: نجد اشتراط الطهارة، والنية، وستر العورة، واستقبال القبلة، وجملة الأقوال والأفعال التي تصح

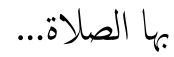

كما نجد كذلك صيغة التراضي بين المتعاقدين سواء عن طريق التلفظ بالإيجاب والقبول، أو عن طريق النية والمقصد، وعن طريق ما يفهم منه أنه من قييل صيغة التراضي، كما هو الحال في بيع المعاطاة عند المالكية وغيرهم، تلك الصيغة تعد وسيلة ثابتة إلى تحقيق مقصود البيع الذي يتصل بالانتفاع المتبادل بالثمن والمثمن، وتخليص المعاملة من الضرر، والغبن، والتغرير، والتزييف، وما أشبه ذلك.

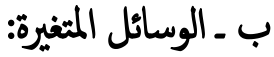

وهي الوسائل التي تتغير بتغير الحال والظرف، والتي تثبت صلاحيتها لمقاصدها عن طريق الاجتهاد، وهي تشمل سائر المجالات التثريعية الظنية والاحتمالية التي تعددت معانيها وصورها وكيفياتها، أو المجالات التي لم توجد نصوص وأحكام تجاهـا. ووهي طرق غير ثابتة والتي تتعين طرقا إلى مقاصدها بطريق الاجتهاد المضبوط حسب تغيرات الأوضاع، وطروء المستجدات، وطبيعة النصوص، وملكة الفقيه وأحواله... ويكون دور المجتهد متمثلا في تحديد الوسائل إلى المقاصد، أو في تحديد أحسن الوسائل إذا تعددت وتداخلت وتعينت جميعها طرقا إلى مقصد واحد، أو مقاصد كثرة. وهي تشمل عموما جملة الكيفيات والطرق التي تخدم الاعتقاد والعبادات والمعاملات، وسائر المسائل الاجتهادية الظنية التي تقبل التأويل والترجيح، والنظر في جوانب الوسائل المفضية إلى مقاصدها. ومن أمثلة هذا النوع ما يأتي: ـ ترك البيع والثراء، واللهو، واللعب، وسائر ما يشغل عن إدراك الجمعة... كل ذلك وسيلة إلى تحقيق مقاصد قداسة المجعة واغتنام منافعها قال ابن العربي في أحكامه بعد أن ذكر عن ابن القاسم عدم فسخ النكاح، وعدم الهبة، والصدقة، ״والصحيح فسخ الجميع؛ لأن البيع إنما منع منه للاشتغال به فكل أمر يشغل عن الجمعة من العقود كلها فهو حرام شرعا مفسوخ ردعاه. ـ التعازير المختلفة التي يتخذها الحاكَ بقصد الردع والزجر ، هي وسائل اجتهادية إلى تحقيق ذلك المقصد، إذ يبحث الحلاك في تحديد أقوى الوسائل وأجداها في تحقيق المقصد وتثييته. ـ الإجراءات والتدابير التي يقيد بها الحاك بعض المباحات بهدف تحقيق المصلحة، هي وسائل إلى إقرار تلك المصلحة. 
وبهذا تكون الوسائل الاجتهادية موطنا رحبا لإعال العقل والنظر ، وبحث أنجع المسالك، وأقرب الطرائق ، وأحسن الكيفيات إلى تحصيل المنافع والمصاح، ودرء المفاسد والمضار ، وفق مقصود الشارع ومراده، إذ أن الوسائل قد شرعت؛ لأن بها تحصيل أحكام أخرى، فينبني حينئذ لزوم خدمتها للمقاصد وتديمها لها. 3ـ أثر الاستحسان في بعض التطبيقات الطبية المعاصرة: نختار ثلاث مسائل:

\section{أ ـ مسآلة نقل العضو من الميّ إلى الميّ:}

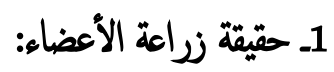

ويراد بها: نقل عضو سليم، أو مجموعة من الأنسجة، من متبرع إلى مستقبل، ليقوم مقام العضو، أو النسيج التالف

عند المستقبل.

وغاية هذه العملية إيجاد عضو مفقود عند المنبرع له، أو إعادة شكله، أو وظيفنه المعهودة، أو إصلاح عيب، أو إزالة

$$
\text { دمامة تسبب للشخص أذنى نفسيا، أو عضويا. }
$$

مسألة نقل وزراعة الأعضاء، والتبرع بها ليست جديدة لهذا العصر، إنما هي موجودة في كتب الفقه القديمة، لكن باسم

$$
\text { آخر ، فقد تحدث عنها الفقهاء تحت عنوان: „الاتنفاعه . }
$$

ـ نقل الدم من سليم إلى مريض، أو التبرع بالكلية من قادر على الاكنفاء بكلية واحدة، إلى عاجز لا تقوم حياته بكليته الموجودة، أو أخذ جلد من جسم إنسان إلى آخر، لزراعته بدل التالف، أو المشوه، أو المحروق، إلى غير ذلك من الأمثلة المتعددة.

والنظر الاستحساني في المسألة، يظهر من خلال معرفة لحتيقة نقل الأعضاء، أن فيها معارضة لقاعدة تشريعية كلية، تتمثل في أن الإنسان لا يملك جسمه، ولا أعضاءه، حتى يتبرع به، وليس له أن يتصرف في هذا الجسم بأي تصرف ناقل للملكية معاوضة، أو تبرعا، كونه لا بملكه ابتداءً. ومصدر، أو سند هذه القاعدة: أن جسد الإنسان قد تعلّق به حق الله وحق العبد، وحق الله فيه أغلب، ودلّ على ذلك عدة نصوص، منها تحريم الشارع للانتحار لما فيه من تصرف في حق الله تعالى بما لا يرضاه سبحانه ولا يقبله، وهذا واضح في قوله 


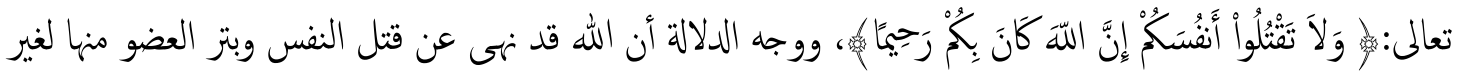
مصلحتها، وقد يؤول إلى قتلها.

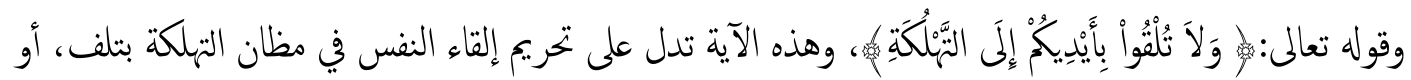
إضعاف من غير مصلحة مقصودة شرعا غير مرجوة. وقوله صلى الله عليه وسلم: امن قتل نفسه بحديدة فحديدته في يده يتوجأ بها في بطنه في نار بهنم، خالدا مخلدا فيها أبدا، ومن شرب سلا فقتل نفسه فهو يتحساه في نار جهنم خالدا مخلدا فيها أبدا، ومن تردى من جبل فقتل نفسه فهو يتردى في نار بهنم خالدا مخلدا فيها أبدا؛؛ لأن الذي يقتل نفسه يعتدي على حق الله تعالى. وبناءً على هذه الأدلة قرر الإمام القرافي، حرمة التصرف في جسد الإنسان نقلا، أو تبرعا فقال: اوحرم القتل والجرح صونا لمهجته، وأعضائه ومنافعها عليه، ولو رضي العبد بإسقاط حقه من ذلك لم يعتبر رضاه، ولم ينفذ إسقاطه؛. وأيّده الشاطبي في هذا المعنى بقوله: افإذا أكمل الله على عبد حياته، وجسمه، وعقله، التي بها يقيم النكاليف لا يصح إسقاط شيء منها《.

وهذا كله لتعلق حق الله في الأعضاء، فلا يملك الإنسان بحسب هذا الأصل ملكة التبرع، أو سلطة التمليك، أو صلاحية النقل.

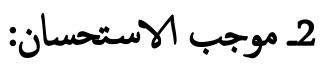

قبل الشروع في بيان موجب الاستحسان في المسألة، يستحسن توضيح المقصود بحق الله عز وجل وهو: ما يتعلق به النفع العام، دون أن يختص به شخص معين، ويقوم حق الله في جسد الإنسان من بحة ما يقوم به العبد من أفعال ترتدُ إلى إقامة المصالح العامة للأفراد المعبر عنها "بجق اللهش، 》إذ لا تحقق مصاح الجماعة، إلا بواسطة أنفس أفرادها، بأرواحم، وأدمنتهم، وأعينهم، وقلوبه، وكل عضو من أعضاء كل فرد من أفراد الجماعة، يسهم بأقدار متفاوتة في تحقيق مصالح الجماعة وحجايتها.... وبناءً على هذا المفهوم يعلم أن في إعادة وظيفة الأعضاء التالفة إلى ماكانت عليه، عن طريق النقل والزرع، ورعاية لحق الله عز وجل، فكما أن أعضاء المتبرع تسهم في النفع العام والمصلحة العامة فتقيم حق الله عز وجل في الوجود، فكذلك هي أعضاء المتبرع له تقوم بذات الوظيفة بداهةً، وترتدُ انتهاءً إلى إقامة ذات المصالح والمنافع. 
فإن الموجب للاستثناء والعدول، هو النظر في مدى إقامة حق الله في حال التبرع، وهذا النظر يرشد إلى أن إقامة حق الله عز وجل في حالة نقل الأعضاء وزرعها، هو آكد وأعظم، من حال إمساكها دون تبرع، ذلك أن في التبرع دفعا لمفسدة عظىى عن حق الله عز وجل المتعلق بجسد المتبرع له بتحمل مفسدة أخف عن حق الله في جسد المتبرع. فكان النبع إذاً وسيلة متعينة لإحياء حق أعظم الله تعالى في الموضع المنقول إليه. إن موجب الاستحسان في المسألة يتلخص كالآتي:

ـ ـ إن في قطع هذه الجزئية عن الأصل العام المتّضي للحظر ، إقامة لحت الله عز وجل بشكل اكد وأظهر من إلحاقها بالأصل الكلي والقياس العام، ولنا جاز العدول والاستثناء.

وقد برع العز بن عبد السلام عندما التفت إلى هذا الموجب المتضي للاستثناء»الاستحسانه في عدة أمثلة منها: - اوأما ما لا يكن تحصيل مصلحته إلا بإفساد بعضه فكقطع اليد المتكاكة حفظا للروح إذاكان الغالب السلام، فإنه يجوز قطعها، وإن كان فيه إفسادها، لما فيه من تحصيل المصلحة الرابحة وهو حفظ الروح". ـ"وإذا وجد المضطر إنساناً ميتاً أكل لمحه، لأن المفسدة في أكل لحم ميت الإنسان، أقل من المفسدة في فوت حياة الإنسان؛. إلى غير ذلك من الأمثلة التي تبين تنبيه الإمام العز إلى أنه يموز العدول عن حق الله عز جل في بعض الوقائع الخاصة، إذكان في هذا العدول وسيلة لإقاذ حق الله عز وجل من بجة أخرى بشكل أعظم وأكبر.

\section{3ـ شروط وضوابط شرعية للنقل والتبرع من الميّ إلى الميّ:}

يشترط في النقل والثبرع الآتي:

أولاً: الضرورة القصوى للنقل، بجيث تكون حالة المنقول إليه المرَضيَّة في تدهور صحي مستمر، ولا يُنقذُهُ من هلاكٍ محقِ إلإ نقلُ عضو سليم إليه من إنسان آخر بينها درجة قرابة حتى الدرجة الثانية، وييوز النقل حتى الدرجة الرابعة إذا حالت ضرورة دون النقل من الدرجات السابقة، ويقدر ذلك أهل المبرة الطبية العدول، شريطة أن يكون المأخوذ منه وافق على ذلك حال كونه بالغًا عاقاً مختارًا . ثنائًا: أن يكون هذا النقل حمِقًِا لمصلحة مؤكدة للمنقول إليه من الوجهة الطبية ويمنع عنه ضررًا مؤكدًا يحل باستمرار بالعضو المصاب، ولا توجد وسيلةٌ أخرى لإنقاذه من الموت والهلاك الحالِّ المحقَّق ؛إلابذا الفعل.

ثالثًا: ألا يؤدي نقل العضو إلى ضرر محقَّ بالمنقول منه يضرُ به كليًا أو جزئيًا، أو يمنعه من مزاولة عمله الذي يباثره في الحياة ماديًا ومعنويًا، أو يؤثر عليه سلبيًّا في الحال أو المهل بطريق مؤكد من الناحية الطبية؛ كأن يكون العضوُ المنقول أساسًا في 
الحياة، مثل القلب والكبد وغيرها؛ لأن مصلحة المنقول إليه ليست بأولى ـ من الناحية الشرعية ـ من مصلحة المنقول منه؛ لأن الضرر لا يُزال بالضرر، ولا ضررَ ولا ضرار في الإسلام، ويكفي في ذلك المصلحة الغالبة الرابحة، والضرر القليل المحتمل عادةً وعرفًا وشرعًا لا يمنع هذا الجواز في التزخيص إذا تح العلم به مسبقًا وأمكن تحمله أو الوقاية منه ماديًا ومعنويًا بالنسبة للمنقول منه، واللذي يجدد ذلك هم أهل الخبرة الطبية العدول .

رابعًا: أن يكون هذا النقل دون أي مقابل مادي، أو معنوي مطلقًا بالمباشرة، أو بالواسطة؛ حتى يكون بعيدًا عن البيع والشراء والتجارة؛ كي لا يتحول جسم الإنسان الذي كرمه الله إلى "قطع غيار "، وتتحول إلى تجارة، فيكون التبرع دون مقابل مادي مطلفًا للمعطي صاحب العضو إن كان حيَّا أو لورثنه إن كان مينًا . خامسًا: صدور إقرار كتابي من اللجنة الطبية ـ قبل النقل ـ بالعلم بهذه الضوابط وإعطائه لذوي الشأن من الطرفين المنقول منه العضو والمنقول إليه قبل إجراء العملية الطبية على أن تكون هذه اللجنة متخصصةً ولا تقل عن ثلاثةِ أطباءٍ عدولٍ ، وليس لأحد منهم مصلحة في عملية النقل .

سادشًا: يشترط آلا يكون العضو المنقول مؤديًا إلى اختلاط الأنساب بأي حال من الأحوال. سابعا: أن لا يكون تنفيذ عمليات التبرع سببا للإساءة إلى الكرامة الإنسانية، ويتصور ذلك في حال استعال الأعضاء للاتجار ، والتكسب، والربح.

\section{ب ـ مسألة الانتفاع من الأجنة المجهضة الميتة:}

قبل بيان صور المسألة يستحسن تعريف الجنين، والإجماض:

الجنين في اللغة: هو الولد في البطن، والجمع أجنة، وأجنن، وهو مشتق من جن، أي استتر ، وسمي جنينا لاستتاره في بطن أ.

والجنين في الاصطلاح: يحمل نفس المعنى اللغوي، غير أن بعض الفقهاء قصره على الحمل الذي يتيين منه شيء من خلق الآدي.

والإجحاض في اللغة: مصدر أجحض، وأبحضت المرأة ولدها أسقطنه ناقص الخلق، والإجحاض: الإزلاق، والجهيض:

السقيط، يقال أبجضت الناقة: أي أسقطت فهي مجهض، فإن كان من عادتها فهي مجهاض. وفي الاصطلاح: إذا رجعنا إلى كتب الفقه نجد أن العلماء يعبرون عنه بالإسقاط، والطرح، والإلقاء، بدلا من إججاض، وإن كان الشافعية يكثر استعالهم للفظ إجهاض.

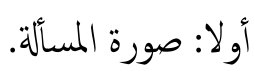


أثبتت الدراسات والبحوث في المجالات الطبية الحديثة، النظر في مدى شرعية الانتفاع من الأجنة المجهضة، وذلك لما في الانتفاع بها من فوائد متعددة تتمثل في مجالين:

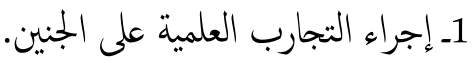
2ـ الاستفادة من أعضاء الجنين لغرسها لإنسان آخر. ومحل البحث هنا، في الأجنة الميتة التي حملت بها المرأة لفترة من الزمن، واستقرت في الرمى ثُ أبحضت لعارض ما، دون تعمد الإجحاض، أو قصد له، من أجل الاستفادة منه لهذه الغايات الطبية. وهذه الأجنة على قسمين: 1ـ أجنة أبهضت قبل نفخ الروح فهيا. 2 أجنة أبهضت بعد نفخ الروح. في كلا القسمين ترجى الاستفادة من هذه الأجنة في العديد من الدراسات الطبية، بشرط حياة خلاياها، وتمتد الاستفادة منها إلى العديد من المجلات، على سبيل المثال استخدام أعضاء الأجنة مثل الكبد والرئتين، والكلى، لإنتاج اللقاحات الفيروسية الخختلفة، واستخداها لدراسة كيفية تكوين عناصر الدم المختلفة والاستفادة منها لتطوير علم المناعة، والغدد الصماء.

وإذا نظرنا إلى صورة الواقعة، يظهر لنا، تعارضها مع ما قرره الشارع من حق للجنين من وجوب النكريم والرعاية له،

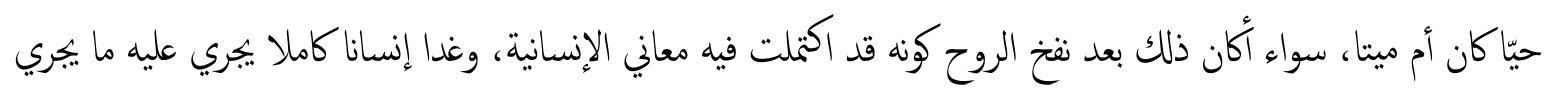
على أيّ إنسان متوفى، أمكان قبل فنخ الروح، كونه قد جمع أصل الإنسان ومادته، وهو وإن لم يكن إنسانا كاملا في تلك الحالة، إلا أنه يجمع من معاني الإنسانية ما يوجب احترامه وتكريمه.

ثانيا: موجب الاستحسان في المسألة.

من باب الاستحسان عرض لهذا الأصل الذي سبق ذكه موجب اقتضى قطع المسألة عن حكم نظائرها وإخراجما

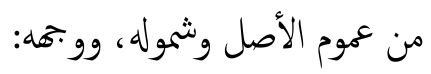
1ـــ إن ماكان حقا للجنين فإنه يورث بموته، عينيا كان هذا الحق أم معنويا، وحقه في التكريم هو من الحقوق المعنوية، التي تنتقل بعد موته إلى مورثه، ويغدو هذا الوارث خُوّلا بالدفاع عنها، أو التنازل عنها، فإذا كان اقتطاع عضو من الجنين، أو كون تعريضه للتجارب العلمية، مخلا بكرامته من حيث هو إنسان، إن كان قد نفخ فيه الروح، أو من حيث هو مادة الإنسان إن 
كان قبل نقخ الروح، فإن هذا الحت يؤول بسبب موته إلى ورثه، فإن شاؤوا منعوا وجوه الانتفاع تلك، وإن شاؤوا تجاوزوا حقهم، وسمحوا بإجراء العمليات تحقيقا للمصاح الكبيرة التي ترجى منها. وقد قرر العديد من الفقهاء من أن موت المقذوف قبل مطالبته بحقه في إقامة الحدّ على القاذف، ينقل هذا الحق إلى

$$
\text { الورثة، فإن شاؤوا أقاموا الدعوة وطالبوا بإقامته الحدّ إقامة لحق مورثهم، وإن شاؤوا عفوا. }
$$

2ـ ويقوم هذا الأصل كذلك إضافة إلى هذا الموجب للاستثناء والاستحسان، بموجب آخر وهو أن المصالح المتوخاة من وراء الانتفاع بالأجنة مصالح ضرورية، ترجع إلى حفظ النفس الإنسانية لدفع غوائل الأمراض الخطيرة عنه، كالسرطان، وعقم الرجال، أو تقوية الجهاز المناعي عند الإنسان، وهذه المصلحة الضرورية تربو على المصلحة التحسينية، التي ثكمن وراء المساس

$$
\text { بالجنين الميت المجهض. }
$$

3ـ الانتفاع بالأجنة راجع إلى مد الحياة الإنسانية بأسباب البقاء والاستمرار والدوام، وأما مآل الامتناع عن الانتفاع، فهو تحلل الجنين وفساده. وهذا يجعل الاستحسان يفوق مصلحة الأصل، الأمر الذي بهدي إلى صحة هذا الاستحسان ومشروعيته.

\section{ج - مسألة التلقيح الصناعي بين الزوجين: أولا: مفهوم التلقيح الصناعي:}

التلقيح الصناعي هو: عملية طبية تتمثل في إخصاب المرأة عن طريق حقن السائل المنوي للرجل في رمها. والغرض منه هو علاج العقم عند المرأة وكذلك الرجل، ويتحقق ذلك: بإدخال مني زوجها، أو مني شخص آخر أجنبي عنها في عضوها التناسلي بواسطة شيء آخر غير المواقعة سواء بالطريق الطبي، أو بغيره. ثانيا: صور التلقيح الصناعي: التلقيح الصناعي له صورتان: تلقيح داخلي، وتلقيح خارجي. أولا: التلقيح الصناعي الداخلي: يتم في هذه الحالة إدخال مني الزوج إلى داخل رحم الزوجة بوسائل طبية معينة، حيث يؤخذ السائل المنوي حارا غبر بارد بعد وضعه في إناء نظيف معقم، غير مبلل بالماء، ويسحب بمحقن خاص ليزرق في فوهة عنق الرحم ليدخل إلى الرحم رأسا، وتترك المرأة بعدها ممدودة على ظهرها مدة ساعة تقريبا لتساعد النطف على الوصول إلى الجهاز التناسلي، حيث تنتظرها البويضة في البوق، ولا تجرى هذه العملية، إلا في اليوم المحدد للتبيض، أي يوم خروج البويضة من 
المبيض، ويستطيع الطبيب تحديد هذا اليوم بمراقبة حرارة المرأة طيلة الشهر، ومراقبة دوراتها الطمثية لأشهر ثلاث سابقة، أو بوضع الأوراق الملونة على عنق الرحم، والتأكد من وجود السكر ، أي انطلاقة البويضة. ويضطر الطبيب في بعض الحالات النادة إلى الالتجاء إلى النقيج الصناعي كتدبير أخير للتخلص من عقم الرجل، كأن يكون الرجل عنينا طاعنا في السن راغبا في الذرية، أو يكون سريع الإنزال لا يستطيع إيصال سائله المنوي إلى داخل أغوار المهبل، أو تكون المرأة حساسة خائفة بشكل يتضيق معه همبلها وتنقبض عضلاتها ما لا يسمح للعضو المذكر بالدخول إلى تلى

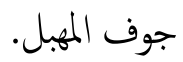

ثنانيا النلقيح الصناعي الخارجي: يتم في هذه الحالة مجع الحيوان المنوي مع البويضة خارج الرجم في أوان، أو أنابيب، أو رمج صناعية، حيث تؤخذ بويضات ناضجة من المبيض بعد تنشيطها بواسطة حقن هرمونية، وتوضع في أنبوب خاص يكتوي على سائل فسيولوجي مناسب، ثم تضاف إليه حيوانات منوية طازجة وتترك حتى يكصل التخصيب، وعندما تصبح الزييوت النطفة الأمشاج ثنائية الخلية، أو رباعيتها تنقل البويضات الملقحة عن طريق المهبل إلى داخل الرحم للعلوق. تتطلب العملية لزوما، انكشاف المرأة والاطلاع على عورتها للقيام بالإجراءات اللازمة. والنظر في آلية العملية، أن فيها معارضة لقاعدتين وقياسين كليين: ـ أما الأولى فهي: ما تقرر في أصول الفقه وفروعها من حرمة كثف العورات ومنع الاطلاع عليها، وعملية التلقيح الصناعي الداخلي والخارجي، لا تخلو من ضرورة كثف العورة لإكمال إجراءات العملية التي تقدم بيانها. ـ وأما القاعدة الثانية فهي: أن الأصل في إنجاب الأولاد وإيحاد الذرية، أن يتم عن طريق المعاشرة الزوجية بين رجل وامرأة تحل له شرعا، دون تدخل عنصر ثالث بينها، لما في دخول طرف ثاثث من خخطر ومفاسد قد تورث الشك في النسب. وإذا انطلقنا إلى تعيم هاتين القاعدتين واطرداهـا، فإن الحكى الشرعي في العملية تكون الحظر والمنع. توجد أمام هذه المقررات العامة، موجبات خاصة تقتضي العدول بهذه الواقعة من القياس الكلي، والقاعدة العامة، وتجعل لهذه الواقعة مناطا خاصا خخالفا للمناط العام المتضضي للمنع وتفصيل ذلك كالآتي: 1ـ إنه إذا كان القاعدة العامة توجب حرمة كثف العورات ومنع النظر إلها، حفاظا على مصلحة تحسينية، ترجع إلى المحافظة على مكارم الأخلاق، وفضائل الآداب، ومحاسن المروءات، فإنه في مقابل هذا الأصل التحسيني تنهض ضرورة إنسانية تتمثل في إيجاد نسل هذين الزوجين، ومن المقرر أصوليا أن الحفاظ على النسل هو أحد الضروريات المّسة التي لا تقوم الحياة إلا 
2ـ هذا ، فإن في هذه العملية التي سبق ذكرها تلبية لمصلحة حاجية، ذلك أن الرغبة في الأبوة والأمومة رغبة فطرية جبلية لا

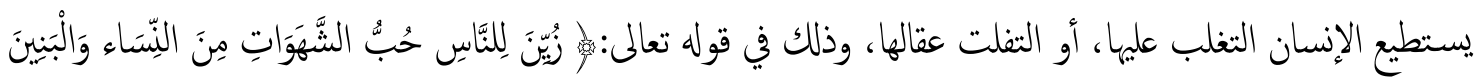

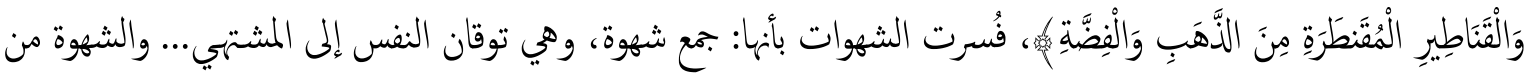
فعل الله، ولا يقدر عليها أحد من البشر، وهي ضرورية فينا، فإنه لا يكننا دفعها عن نقوسنا، وقد زينها الله تعالى لم بما جعل في الطباع من الميل إليها، وبما خلق فيها من الزينة محنة وتشديدا للتكليف. وزين الله تعالى حب البنين وتربيتهم لكي يطلب البشر التناسل ويقوموا بالمشقات المعروفة في نفتهم وتربيتهم، وحسن

$$
\text { المداراة لمم في تربيتهم والنظر إلى إصلاح أمورهم وعواقهه. }
$$

وهكذا فإن طلب الولد أمر فطري، فطر الله عليه النوع الإنساني سواء في ذلك الصالح والطالح، والنبي ومن دونه،

$$
\text { وقد جهز الجميع بجهاز التوالد والتناسل وعزر فيهم ما يدعوهم إليه. }
$$

فنجد أن في العدول عن موجب القياس المقتضي لحرمة كثف العورات في نازلة التلقيح الاصطناعي، دليلا ينهض بشرعية هذا العدول والاستثناء، هو هنا المصلحة الضرورية والمصلحة الحاجية، وهذا ما أدركه العلماء في هذه القضية حيث بينوا بأن الغرض المشروع في الحصول على الولد سواء في ذلك رغبة الزوج أم الزوجة، يمكن أن يعتبر مييحا لانكشاف الزوجة في سبيل العقم، أو التنقيح الصناعي.

ونص عليه بمع الفقه الإسلاي ميينا ومقررا صحة هذا العدول والاستثناء، أي الاستحسان، أن احتياج المرأة إلى العلاج من حالة غير طبيعية في جسمها، تسبب لها إزعاجا يعتبر ذلك غرضا مشروعا يبيح لها الانكشاف على غير زوبحا لهذا العلاج، وأن حاجة المرأة المتزوجة التي لا تحمل، وحاجة زوجها إلى الولد، تعتبر غرضا مشروعا بييح معالجها بالطريقة المباحة من طرق التلقيح الاصطناعي. ويظهر من هذا كله كيف تجلى الاستحسان في العدول بهذه المسألة من الحظر إلى الإباحة، لموجب قوي احتف هذه الواقعة، هو الحفاظ على مصلحة الضرورة ومصلحة حاجية. ثالثا: شروط التلقيح الاصطناعي: هذه العملية التي سبق ذكها، قامت على مبدأ الاستحسان وهي تحتوي كذلك على عدة شروط منها: 1ـ أن يتم التلقيح من مني الزوج نفسه وفي رحم الزوجة نفسها. 2ـ أن يثبت بناءً على تقرير طبي من طبيب متخصص أن الزوجة لا يكنها الحمل، إلا بهذه الطريقة. 
3ـ أن يتم في حياة الزوج، وليس بعد وفاته على أساس أن الزوج حين يموت يصبح غريبا عن زوجته لانقطاع رابطة الزوجية بالوفاة وبذلك يعتبر التلقيح منه محرما.

4ـ أن تتم العملية بغرض مكاحة العقم، والتغلب على آثاره الضارة، وليس بقصد التحكم من جنس الجنين، أو تغيير صفاته الوراثية.

5ـ اتخاذ جميع الاحتياطات اللازمة لعدم اختلاط النطف، وعدم الاحتفاظ بالمني في الثلاجات؛ بل إجراء التلقيح فور أخذه من الزوج وإعطاءه للزوجة. 6ـ أن يكون الطبيب الذي يقوم بالعمل، والفريق المساعد له من الممرضين ، وعال الخختبرات مسلمين ومؤتمنين. على أساس أن الطبيب غير المسلم قدييز لنفسه استخدام الحيوانات المنوية لشخص غريب.

إن الفته المقاصدي ليس علما جديدا، ولا مبتدعا على ديننا الحنيف كما فكر البعض وإنما علم قديم أقزّه القرآن الكربم، وتحدث به رسولنا الكريم عليه أفضل الصلاة وأزكى التسليم، ومارسه التابعون، وتمسك به العلماء بعد ذلك إلى يومنا هذا. الفته المقاصدي له أهمية كبيرة، وأثر ظاهر في الاستحسان، كما أنه ذو أهمية بالنسبة للفقيه المجهد لفهم النصوص ومعرفة دلالتها، واستنباط الأحكام الشرعية للمسائل والنوازل التي لانص فيها. تظهر علاقة الفقه المقاصدي واضحة بالاستحسان، في الاستحسان بالضرورة عند الحنفية، من خلال كون الاستحسان العدول بالمسألة عن نظائرها، ولا يعدل بالمسألة عن نظائرها، إلا لتحقيق مصاح أعظم ودفع المفاسد. الفقه هو ثرة الاجتهاد في الثريعة الذي رسم الرسول عليه الصلاة والسلام، أسسه في عصر الرسالة. فقد ثبت أن من أهم حِكم اجتهاده صلى الله عليه وسلم هو وضع منهج سليم للعاملين بالفقه والاجتهاد. يعد ابن القيم وابن عاشور رائدى علم المقاصد تطبيقا، كما أن الإمام الشاطبي منظر علم المقاصد. إن للشريعة مقاصد عامة تشتمل على عبادة الله، وجلب المصاح ، ودرء المفاسد، ورفح الحرج، والعدل وغير ذلك.

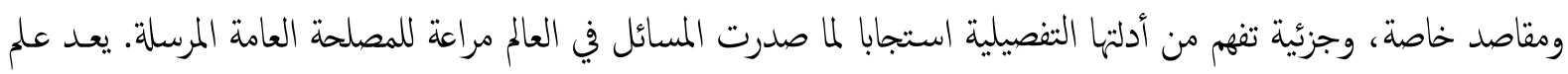
المقاصد من أهم حلقات العلوم الخادمة للاجتهاد لدوره في فهم أسرار الشريعة وحِكمها، وهو ما لا استغناء للمجتهد عنه. 
1. الجامع الكبير، أبو عبد الله محمد بن الحسن الشيباني ، مطبعة الاستقامة. 2. أصول الفقه الإسلاي، زكي الدين شعبان، عام 1995م، منشورات جامعة قاريونس ـ بنغازي.

$$
\text { 3. . قواعد الأحكام في مصاح الأنام، العز بن عبد السلام، ج2. }
$$

5. القواعد الكبرى، العز بن عبد السلام، ج1، ط1، عام 1421هـ/2000م، دار القلم ـ دمشق.

6. الفروق، شهاب الدين أبو العباس الصنهاجي المشهور بالقرافي، ج2. 7.

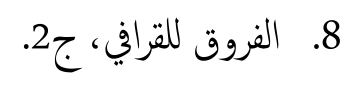

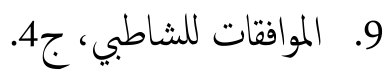

10. بجلة التواصل، محاضرة الشيخ محمد الحبيب بالخوجة، السنة الثانية، العدد السابع، تصدر عن جمعية الدعوة

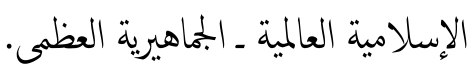

$$
\text { 11. أحكام القرآن ، أبو بكر محمد بن عبد الله بن العربي، ج4. }
$$

12. مجلة مؤتة للبحوث والدراسات، المجلد 16، العدد الأول، عام 2001م، إعداد عبد الرحمن زيد الكيلاني، تصدر عن بكن بكري جامعة مؤتة ـ الأردن. 13. مجلة بمعح الفقه الإسلايي، الدورة الرابعة، عام 1408هـ/1988م، العدد الرابع، ج1.

$$
\text { 15. 14. البحر الرائق، ج1، دار المعرفة ـ بيروت. }
$$

16. الموافقات للشاطبي، ج2، ص376، والفروق للقرافي، ج1.

17. شرح التلويح على التوضيح، سعد الدين مسعود بن عمر التنتازاني، ج2، دار الكتب العلمية ـ بيروت. 18. أبحاث فقية في قضايا طبية معاصرة، محمد نعيم ياسين، ص154، ط2، عام 1419هـ/1999م، دار النفائس.

$$
\text { 19. قواعد الأحكام في مصاح الأنام للعز بن عبد السلام، ج1. }
$$


20. أبحاث فقهية في قضايا طبية معاصرة، محد نعيم ياسين، حكم الانتفاع بأعضاء الإنسان، مجلة الفقه الإسلايي، إعداد محمد رمضان البوطي، العدد الرابع، عام 1408هـ/1989م، وقرارات بجلس المجمع الفقهي لرابطة العالم الإسلامي 21. قضايا فقهية معاصرة، تأليف لجنة من أساتذة قسم الفقه المقارن بكلية الشريعة والقانون - ج1، مصر.

$$
\begin{aligned}
& \text { 22. المعجم الوسيط، قام بإخراجه: إبراهيم مصطفى، أحمد حسن الزيات...، ج1، } \\
& \text { 23. خختار الصحاح، محد بن أبي بكر الرازي، ج1 } \\
& \text { 24. بدائع الصنائع للكساني، ج7. } \\
& \text { 25. لسان العرب لابن منظور، ج1. }
\end{aligned}
$$

26. موسوعة الفقه الإسلامي، ج3، ص158، عام 1414هـ/1993م، يصدرها المجلس الأعلى للشؤون الإسلامية ـ مصر. 27. البحر الرائق كنزالدقائق، زين الدين ابن نجيم الحنفي، ج8، ط3، عام 1413هـ/1993م، دار المعرفة ـ بيروت. 28. مجلة بمحع الفقه الإسلايي، إجراء التجارب على الأجنة المجهضة تلقائيا، إعداد محمد علي البار، العدد السادس، عام

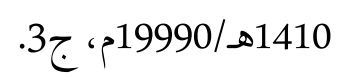

29. مجلة الفقه الإسلايي، القرار رقّ 6/7/58، سنة 1410هـ /1990م، العدد السادس، ج3. 30. شرح صحيح مسلم للنووي، ج16، ص191، دار الثقافة العربية ـ بيروت، وفنح الباري لابن الحجر، ج11،، دار

$$
\begin{aligned}
& \text { 31. الأحياء التراث العربي - بيروت. الشرعية لبلحاج. }
\end{aligned}
$$

32. قضايا فقهية معاصرة، للبوطي، ط3، عام 1413هـ/ 1992م، مكتبة الفارابي ـ دمشق.

33. الحاوي الكبير، أبو الحسن بن علي بن محد بن حبي الماوردي، عام 1414هـ/1994م، دار الكتب العلمية ـ

$$
\text { بيروت. }
$$

34. مجلة مجمع الفقه الإسلاي، العدد السادس، ج3، قرار رقة: 6/7/58. 35. التلقيح الصناعي وأطفال الأنابيب والرأي الشرعي فيها، مصطفى أحمد الزرقاء، بحث مقدم إلى المجمع الفقهي، عام 1400هـ/1980م، مكة المكرمة. 36. التلقيح الصناعي وأطفال الأنابب، محد علي البار، ج1، ص271، مجلة الطبيب، العدد 2، عام1987م، تشرين

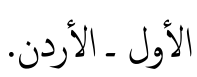


محمد أغوس جوهري

37. مجلة مجمع الفقه الإسلايي، العدد1، المجلد السادس عشر، عام 2001م، إعداد عبد الرحن زيد الكيلاني. 38. المفردات للراغب الأصفهاني، وتفسير المنار لمحد رشيد رضا، ج3، ط4، عام 1379هـ/1960م، مكتبة القاهرة. 39. مجلة مجمع الفقه الإسلاي، العدد الثالث، ج1، ص515، وانظر قرارات مجلس المجمع. 